\title{
Chapter \#1
}

\section{THE RELATIONSHIP BETWEEN STUDENT'S APPROACHES TOWARD LEARNING AND ACADEMIC ACHIEVEMENT IN THE CHINESE CONTEXT}

\author{
Chuang Wang', Qimeng Liu ${ }^{2}$, Jian Liu ${ }^{2}, \&$ Tianxue Cui ${ }^{1}$ \\ ${ }^{1}$ Faculty of Education, University of Macau, China \\ ${ }^{2}$ Collaborative Innovation Center of Assessment for Education Quality, Beijing Normal University, \\ China
}

\begin{abstract}
This study examined the relationship between Chinese high school students' approaches toward learning and their academic achievements. Participants consisted of 14,021 eleventh graders from an eastern province in China. They took the National Standardized Test in three subject areas: Chinese language, mathematics, and English language. The total score was used as an indicator of their academic achievement. Students' approaches toward learning were measured in three aspects: self-confidence in learning, learning interests, and study habits. Questionnaires of self-confidence in learning and learning interests were adapted from PISA 2006 and PISA 2012. Study habits were measured with the questionnaire adapted from Academic Adjustment Inventory (AAT). The Pearson correlation and hierarchical linear regression results showed that the dimensions of students' approaches toward learning were significantly related to academic achievements. Results of analysis of variance after the control of student gender and socioeconomic status suggested that the top $25 \%$ of students in dimensions of approaches toward learning scored significantly higher than the bottom $25 \%$ of students with small effect sizes in their performance on the final examinations. This study suggests that helping students build good approaches toward learning may improve their academic achievements. Educators are recommended to put more effort into helping students cultivate learning confidence and developing interests in learning. Classroom teachers are advised to guide students in fostering good study habits and make study plans.
\end{abstract}

Keywords: self-confidence, interests, strategies, academic achievements.

\section{INTRODUCTION}

The aim of education is to promote students' comprehensive development (Anzai $\&$ Simon, 1979). Not only are learning outcomes important, but the quality of learning taking place during the learning process is equally important. It has been unanimously affirmed in educational research that students' approaches toward learning significantly affect their academic performance (e.g., Hugener et al., 2009; Jin \& Si, 2004). For example, McDermott (1984) demonstrated that approaches toward learning could produce larger predictive effects on learning outcomes than intelligence. Most scholars also believe that approaches toward learning such as self-confidence in learning, learning interest, learning motivation, and study habits, are basic qualities that are closely related to and significantly impact learning (e.g., Bai, Chao, \& Wang, 2019; Gorges, Maehler, Koch, \& Offerhaus, 2016; Shen, Yang, \& Fang, 2015). 
Education reform in sizeable countries all over the world has shifted from focusing on academic performance to stimulating and cultivating students' approaches toward learning. For example, the United Kingdom, Germany, Switzerland, Australia, and other countries have started to develop new national curriculum standards on students' approaches toward learning. Many influential international organizations have also conducted empirical research on students' approaches toward learning and analyzed the influencing factors of students' approaches toward learning in different grades through large-scale assessment data. For example, the Programme for International Student Assessment (PISA), Trends in International Mathematics and Science Study (TIMSS), Program in International Reading Literacy Study (PIRLS), and National Assessment of Educational Progress (NAEP) have evaluated students' approaches toward learning in specific disciplines.

Chinese education is academic achievement-oriented, where students, schools, and parents focus on academic performance/test scores, which has caused an academic burden (Zhang, 2000). Therefore, under this specific context, teachers and parents are prone to neglecting the cultivation of students' quality of learning, limiting the comprehensive development of students (Zhou, 2016). Based on China's unique context, it is crucial to explore the relationship between students' approaches toward learning and their academic achievements. It is also important to examine approaches toward learning based on empirical, large-scale assessment data and propose relevant suggestions for education policy in China.

\section{BACKGROUND}

\subsection{Theoretical framework}

Humanistic Learning Theory provided the theoretical basis for this study (Maslow, 1965; Rogers, 1965). It emphasized that learning is student-oriented, which educators need to promote students' all-round development and self-realization. Rogers (1965) believed that meaningful learning should be encouraged. In this optimal learning atmosphere, students' learning quality can continue to positively affect their academic performance and help them achieve outstanding learning outcomes. This theory highlights the importance of students' approaches toward learning.

\subsection{Definition of approaches toward learning}

Various definitions of approaches toward learning exist in the literature. Shenzhen Education Bureau (2014) issued guidance on further improving primary and secondary school students' comprehensive literacy. The guidance defined approaches toward learning as the relatively stable psychological characteristics of learners in the learning process, such as learning motivation, interest, habit, and ability. Other definitions of approaches toward learning include essential student characteristics that encourage them to adapt to life-long learning and future development (Lu, 2017). Peng (2004) referred to approaches to learning as "the way for students to establish a connection with the learning content during learning period" (p. 75), which is one of the factors that affect how students achieve academically and obtain study skills (Cutolo \& Rochford, 2007; Kassab, Al-Shafei, Salem, \& Otoom, 2015). Numerous studies have indicated that approaches toward learning were strongly related to students' academic development and had positive impacts on their learning outcomes (e.g., Angus, 2003; Cutolo \& Rochford, 2007; Denton \& West, 2002; Li, 2019; McGinnis, 2009). 


\subsection{Framework of approaches toward learning}

Approaches toward learning was considered to be a complex system with multiple levels and aspects (e.g., Ge \& Yang, 1997; Lu, 2017). According to Early Learning and Development Benchmarks in Washington State from 2005, there are five dimensions of students' approaches toward learning: curiosity, interest, initiative, persistence and attention, reflection, and interpretation (Kagan \& Kauerz, 2012). The High/Scope Educational Research Foundation in Michigan, sorted students' approaches toward learning into the following six aspects: initiative, planning, participation, problem solving, use of resources, and reflection (Schweinhart, Berruetaclement, Barnett, Epstein, \& Weikart, 1985; Schweinhart, 1993; Schweinhart \& Weikart, 1997).

Studies with Chinese students suggest that approaches toward learning are multidimensional. Zheng (1996) classified approaches toward learning into learning motivation, learning habits, and learning methods. Peng (2004) classified approaches toward learning into learning motivation, learning tendency, learning monitoring, learning strategies, and learning ability. Lu (2017) reported six dimensions of approaches toward learning: (a) learning cognition and experience; (b) learning motivation; (c) learning ability and method; (d) learning persistence; and (e) learning outcomes. After integrating the definition and structure of approaches toward learning from domestic and foreign research, this study measures students' approaches toward learning from three aspects: self-confidence in learning, learning interest, and study habits.

\subsubsection{Self-confidence in learning}

Self-confidence in learning in the current study is defined as students' positive reactions towards their completion of learning tasks and the achievement of learning goals (Xiu, 2009). Studies showed that students who gained more learning confidence scored higher academically, especially when teachers adopted encouraging teaching strategies (Zhong, 2016).

\subsubsection{Learning interest}

Learning interest is defined as individuals' conscious tendency to try to know something and engage in a certain learning activity (Renninger, Hidi, \& Krapp, 1992). Learning interest is the driving force in the learning process; students who have a higher interest in learning can engage more deeply in learning (Yan, 2015).

\subsubsection{Study habits}

Study habits can be described as the adopted strategy and manner a student plans in his/her private learning to attain mastery of one or more subjects (Capuno et al., 2019; Memiş \& Kandemir, 2019). Having good study habits means using suitable learning strategies, which improves students' learning efficiency, thus helping students obtain success and produce better learning results (Capuno, et al., 2019; Ogbodo, 2010).

\subsection{Impacts of social economic status (SES) and gender}

Researchers have identified significant differences in learning outcomes related to students' gender and social economic status (SES) (e.g., McNeal, 2012; Sojourner \& Kushner, 1997). Many studies indicated that SES may positively or negatively predict parental involvement and learning outcomes (Merola, 2005). Studies also suggest differences between boys and girls in learning performance (e.g., Ma, Du, Hau, \& Liu, 2018). As a result, the possible effects of SES and gender on learning outcomes were controlled in this study when examining the relationship between approaches toward learning and academic achievement. 
The current study explores the relationship between approaches toward learning and academic achievement and answers the following research questions:

1. Is there a significant relationship between dimensions of approaches toward learning and students' academic achievement?

2. How do dimensions of approaches toward learning predict academic achievement?

3. Are there differences in learning outcomes among students with various levels of self-confidence in learning, learning interest, and study habits when their SES and gender are the same?

\section{METHODS}

\subsection{Participants}

A total of 14,021 eleventh graders from an eastern province in Mainland China participated in the current study. A stratified cluster random sampling was employed, through which 100 schools from the 17 cities in the province were randomly selected to represent the student population in the province. All selected schools agreed to participate in the study. Due to the school support, the response rate was $100 \%$. Table 1 shows detailed demographic information of the participants.

Table 1.

Descriptive Statistics of Demographic Information.

\begin{tabular}{lcc}
\hline Demographic Variables & N & Percentage (\%) \\
\hline Gender & 6794 & 46.3 \\
Males & 7527 & 53.7 \\
Females & & \\
Birthplace & 6105 & 44.3 \\
Rural & 4637 & 33.6 \\
Suburban & 3048 & 22.1 \\
Urban & & \\
\hline
\end{tabular}

\subsection{Instruments}

\subsubsection{Self-confidence in learning}

The Self-Confidence in Learning scale was adapted from PISA 2006 (Organization of Economic Co-Operation and Development [OECD], 2009) and is intended to measure students' self-confidence in learning with three items. For example, one item was "I believe I can do well in the exam". Students were asked to respond to three items using a four-point Likert scale ranging from 1 (strongly disagree) to 4 (strongly agree). The Cronbach's alpha of responses to this scale was .74. 


\subsubsection{Learning interests}

The Learning Interest Scale was developed by PISA 2012 (OECD, 2013) with the purpose of testing students' interest in courses and reading contents. Students were asked to respond to four items in each subject using a five-point Likert scale ranging from 1 (strongly disagree) to 5 (strongly agree). The internal consistency of the scales measured by Cronbach's alpha were $.94, .96, .96$, and .94 for learning interest of Chinese language, mathematics, English language, and overall learning interests, respectively.

\subsubsection{Study habits}

The Study Habits scale was adapted from Academic Adjustment Inventory (AAT). The scale has 12 items in three dimensions: plan for learning, style of listening, and style of reading. Students responded to the items using a five-point scale ranging from 1 (strongly disagree) to 5 (strongly agree), and higher scores represented better study habits in learning activities. Results showed high internal consistency based on Cronbach's alpha for each dimension and the whole scale: $.93, .90, .94$, and .97 , respectively.

\subsubsection{Academic achievements}

Students' academic achievements were assessed by final examinations. To follow the Chinese National Curriculum Standards, three subject areas (mathematics, Chinese language, and English language) were included in this study. The three subject tests' total score represents students' academic achievements, with a mean of 249.90 and a standard deviation of 27.92 .

\subsubsection{Social economic status (SES)}

We took an example from the method used in PISA 2009 (OECD, 2012) to evaluate SES in the current study. Students were asked to respond to several parental information questions, such as educational level, occupational status, and family possessions. A standardized score was then calculated from the highest degree of parental education, the highest occupational status of parents, and family belongings such as home educational resources.

\subsection{Data collection and data analytic procedures}

Preliminary analyses included the testing of the reliability of students' responses to the instruments. Descriptive statistics, including means and the standard deviations, are provided for the key variables. Pearson correlations and stepwise linear regressions were adopted to explore the relationship between approaches toward learning and academic achievements. An analysis of variance (ANOVA) was used to examine differences in academic achievements between the students in the top 25th percentile and those in the bottom 25 th percentile based on self-reports on self-confidence in learning, learning interests, and study habits, when students' gender and SES were controlled. Effect sizes $\left(\eta^{2}\right)$ were reported using Cohen's (1988) standards for small (.01), medium (.06), and large (.14) effect sizes.

\section{RESULTS}

Results of the Pearson correlation among variables are shown in Table 2. Students' dimensions of approaches toward learning were statistically significantly related to each other. Dimensions of approaches toward learning were also statistically significantly correlated with academic achievements. Table 3 describes the relationship between dimensions of approaches toward learning and academic achievements. Results of a stepwise linear regression indicated that self-confidence in learning, learning interests, and study 
habits all significantly predicted students' academic achievements. The three variables each significantly contributed to the prediction of students' learning outcomes (Table 3). The change of the R-squared value was statistically significant at each step.

In order to further explore students' academic achievements by different dimensions of approaches toward learning, we classified students into the upper and lower $25 \%$ according to the scores of each dimension of approaches toward learning by. The top group represented students who were high in self-confidence in learning, learning interests, or possessed good study habits, and students in the bottom group were those with low self-confidence in learning, learning interest, or poor study habits.

Table 4 shows the results from the ANOVA of students' academic achievements by approaches toward learning (here refers to self-confidence in learning, learning interests and study habits). Significant differences were noted in three domains: students with higher self-confidence in learning $(M=255.25, S D=26.02)$ had higher levels of academic achievements than those with lower self-confidence in learning $(M=243.43, S D=29.78)$, $F(1,6779)=226.68, p<.001$, partial $\eta^{2}=.03$ (small effect size). Students who possessed higher learning interests $(M=255.43, S D=25.89)$ performed better on standardized tests than those with lower learning interests $(M=243.22, S D=29.18), F(1,6980)=211.83$, $p<.001$, partial $\eta^{2}=.03$ (small effect size). Meanwhile, students who had better study habits $(M=253.50, S D=27.15)$ also had higher academic achievements than those with poorer study habits $(M=245.92, S D=28.38), F(1,7643)=84.74, p<.001$, partial $\eta^{2}=.01$ (small effect size).

\section{Table 2.}

Pearson Correlation Coefficients among Self-Confidence in Learning, Learning Interests, Study Habits, and Academic Achievements.

\begin{tabular}{lllll}
\hline & SCL & LINT & STAB & TTS \\
\hline SCL & 1 & & & \\
LINT & $.63^{*}$ & 1 & 1 & \\
STAB & $.58^{*}$ & $.70^{*}$ & $.15^{*}$ & 1 \\
TTS & $.17^{*}$ & $.18^{*}$ & 4.23 & 249.90 \\
$M$ & 3.23 & 4.02 & 0.75 & 27.92 \\
SD & 0.66 & 0.85 & & \\
\hline
\end{tabular}

Notes: (a) SCL = Self-confidence in learning; LINT = Learning interest; STAB = Study habit; TTS $=$ Total score in three subjects $=$ Academic achievement; $(\mathrm{b}) * p<.001$. 
The Relationship between Student's Approaches toward Learning and Academic Achievement in the

Chinese Context

Table 3.

Relationship between Academic Achievements and Self-Confidence in Learning, Learning Interests, Study Habits, and Academic Achievements.

\begin{tabular}{cccccc}
\hline Variable & $\mathrm{B}$ & $\mathrm{SEB}$ & $\beta$ & $\mathrm{R}^{2}$ & $\Delta \mathrm{R}^{2}$ \\
\hline Step 1 & & & & $.03^{*}$ & \\
SCL & 6.19 & .32 & $.17^{*}$ & & \\
Step 2 & & & & $.04^{*}$ & $.01^{*}$ \\
SCL & 3.11 & .42 & $.09^{*}$ & & \\
LINT & 4.29 & .37 & $.14^{*}$ & & $.02^{*}$ \\
Step 3 & & & & $.06^{*}$ & \\
SCL & 2.83 & .43 & $.08^{*}$ & & \\
LINT & 3.65 & .44 & $.12^{*}$ & & \\
STAB & 1.47 & .54 & $.04^{*}$ & &
\end{tabular}

Notes. (a) SCL = Self-confidence in learning; LINT = Learning interest; STAB = Study habit; TTS $=$ Total score in three subjects = Academic achievement; (b) $* p<.001$

Table 4.

Relationship between Academic Achievement (TTS) and Approaches to Learning.

\begin{tabular}{|c|c|c|c|c|c|c|c|c|c|}
\hline & $\overline{S C L}$ & & & LINT & & & STAB & & \\
\hline Indicator & $S S$ & $F$ & 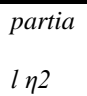 & $S S$ & $F$ & $\begin{array}{l}\text { partia } \\
\ln 2\end{array}$ & $S S$ & $F$ & $\begin{array}{l}\text { partia } \\
l \eta 2\end{array}$ \\
\hline SES & 74885.05 & $\begin{array}{l}100.51 \\
*\end{array}$ & .02 & 74734.07 & $\begin{array}{l}101.40 \\
*\end{array}$ & .01 & 82211.30 & $\begin{array}{l}110.55 \\
*\end{array}$ & .01 \\
\hline Gender & 85990.14 & $\begin{array}{l}115.42 \\
*\end{array}$ & .02 & $\begin{array}{c}103826.2 \\
4\end{array}$ & $\begin{array}{l}140.88 \\
*\end{array}$ & .02 & $\begin{array}{c}138916.8 \\
5\end{array}$ & $\begin{array}{l}186.80 \\
*\end{array}$ & .02 \\
\hline $\begin{array}{l}\text { Approache } \\
\text { s }\end{array}$ & $\begin{array}{l}168885.6 \\
0\end{array}$ & $\begin{array}{l}226.68 \\
*\end{array}$ & .03 & $\begin{array}{c}156121.7 \\
3\end{array}$ & $\begin{array}{l}211.83 \\
*\end{array}$ & .03 & 63017.75 & $84.74^{*}$ & .01 \\
\hline
\end{tabular}

Notes. (a) SCL = Self-confidence in learning; LINT = Learning interest; STAB = Study habit; TTS $=$ Total score in three subjects $=$ Academic achievement (b) $* p<.001$. 


\section{CONCLUSION AND DISCUSSION}

The study was designed to explore the relationship between approaches toward learning and students' academic achievements for Chinese high school students. Results showed that the dimensions of approaches toward learning (self-confidence in learning, learning interest, and study habits) were all significantly related to students' academic achievements (Research Question One). Our findings are consistent with those from previous studies (Cutolo \& Rochford, 2007; Denton \& West, 2002; Li, 2019; Kassab et al., 2015) in confirming the positive relationship between approaches toward learning and academic achievement. Our study contributed to the literature by showing evidence that each of the three dimensions of approaches toward learning (i.e., self-confidence in learning, learning interests, and study habits) significantly predicted students' academic achievements (Research Question Two). Moreover, Research Question Three was also answered with statistically significant differences in students' learning outcomes between various levels of self-confidence in learning, learning interests, and study habits, which echoed previous research (Chang, \& Cheng, 2008; Kaur \& Pathania, 2015; Xiu, 2009; Zhou, 2016).

Approaches toward learning is of great importance to students' academic development (Hugener et al., 2009). It can reflect students' confidence, interest, and other attitudes or behaviors in learning. Lu (2017) demonstrated that approaches toward learning is one of the most profound psychological characteristics that learners should have to contribute to their academic success. Poor learning outcomes are largely related to the absence of learning quality (Peng, 2004). Students with good approaches toward learning tend to show high interests and confidence in the learning process and have relatively viable study habits. They are interested in learning, believe that they are capable of learning, and regard learning as a pleasant behavior.

Attitude and cognition fosters a stable automatic learning behavior through better (Feng, 2002). In order to improve students' academic performance, educators should put more effort into helping students cultivate learning confidence (Li, 2019). Students can learn in a better way when they acquire interesting learning contents (Renninger et al., 1992), so it is also important for educators to help students develop interests in learning. Finally, classroom teachers should guide students in fostering good study habits and establish appropriate plans for learning (including listening to the teachers, reading, and reviewing the contents).

\section{REFERENCES}

Angus, D. (2003). Quality of learning on an MBA programme: The impact of approaches to learning on academic performance. Educational Psychology, 23(2), 123-139. doi: $10.1080 / 01443410303230$

Anzai, Y., \& Simon, H. A. (1979). The theory of learning by doing. Psychological Review, 86(2), 124-140. doi: 10.1037/0033-295X.86.2.124

Bai, B., Chao, G. C. N., \& Wang, C. (2019). The relationship between social support, self-efficacy, and English language learning achievement in Hong Kong. TESOL Quarterly, 53(1), 208-221. doi: $10.1002 /$ tesq.439

Capuno, R., Necesario, R., Etcuban, J. O., Espina, R., Padillo, G., \& Manguilimotan, R. (2019). Attitudes, study habits, and academic performance of junior high school students in mathematics. International Electronic Journal of Mathematics Education, 14(3), 547-561. doi: $10.29333 /$ iejme/5768 
The Relationship between Student's Approaches toward Learning and Academic Achievement in the

Chang, C. Y., \& Cheng, W. Y. (2008). Science achievement and students' self-confidence and interest in science: A Taiwanese representative sample study. International Journal of Science Education,30(9), 1183-1200. doi: 10.1080/09500690701435384

Cohen, J. (1988). Statistical power analysis for the behavioral sciences ( $2^{\text {nd }}$ edition). Hillsdale, NJ: Erlbaum.

Cutolo, A., \& Rochford, R. A. (2007). An Analysis of Freshmen Learning Styles and Their Relationship to Academic Achievement. College Quarterly, 10, 1-17.

Denton, K., \& West, J. (2002). Children's reading and mathematics achievement in kindergarten and first grade. Education Statistics Quarterly, 4, 90. doi: 10.1016/0047-259X(77)90075-6

Feng, H. Y. (2002). Dui gaozhongsheng suexi xiguanxianzhang de diaocha fenxi [Investigating and Analyzing the Present State of Students' Study Habits in Senior Middle Schools]. Sichuan Shifan Xueyuan Xuebao, 3, 114-117.

Ge, M. G., \& Yang, Y. P. (1997). Xiaoxuesheng xuexi pinzhi xunlian de shiyan yanjiu [An experimental study on learning quality training for primary school students]. Anhui Shifan Daxue Xuebao, 3, 98-102.

Gorges, J., Maehler, D. B., Koch, T., \& Offerhaus, J. (2016). Who likes to learn new things: measuring adult motivation to learn with PIAAC data from 21 countries. Large-scale Assessments in Education, 4, 9-31. doi:10.1186/s40536-016-0024-4

Hugener, I., Pauli, C., Reusser, K., Lipowsky, F., Rakoczy, K., \& Klieme, E. (2009). Teaching patterns and learning quality in Swiss and German mathematics lessons. Learning and instruction, 19(1), 66-78. doi: 10.1016/j.learninstruc.2008.02.001

Jin, R., \& Si, L. (2004, July). A Bayesian approach toward active learning for collaborative filtering. Proceedings of the 20th conference on Uncertainty in artificial intelligence (pp. 278-285). AUAI Press.

Kagan, S. L., \& Kauerz, K. (Eds.). (2012). Early childhood systems: Transforming early learning. New York, NY: Teachers College Press.

Kaur, A., \& Pathania, R. (2015). Study habits and academic performance among late adolescents Studies on Home and Community Science, 9(1), 33-35. doi:10.1080/09737189.2015.11885430

Kassab, S. E., Al-Shafei, A. I., Salem, A. H., \& Otoom, S. (2015). Relationships between the quality of blended learning experience, self-regulated learning, and academic achievement of medical students: A path analysis. Advances in medical education and practice, 6, 27-34. doi: 10.2147/AMEP.S75830

Li, Q. (2019). Chuzhong xuesheng de xuexi pinzhi ji qi yingxiang yinsu-jiyu zhejiang sheng mou shi chi yi nianji xuesheng de diaocha [Study quality of junior high school students and its influencing factors - Based on a survey of junior high school students in a city of zhejiang province]. 教育测 量与评价 [Educational Measurement and Evaluation], 7, 45- 53.

Lu, Y. Q. (2017). Xuexi pinzhi pingjia: Jiaoyu zhiliang pingjia de "haidian moshi”" [Evaluation of Learning Quality: "Haidian Model" of Educational Quality Evaluation]. 中小学管理 [Management of primary and secondary schools], 8, 9-12.

Ma, L. H., Du, X. F., Hau, K. T., \& Liu, J. (2018). The association between teacher-student relationship and academic achievement in Chinese EFL context: a serial multiple mediation model, Educational Psychology, 38(5), 687-707, doi:10.1080/01443410.2017.1412400

Maslow, A. H. (1965). Humanistic science and transcendent experiences. Journal of Humanistic Psychology, 5(2), 219-227. doi: 10.1177/002216786500500211

Merola, S. S. (2005, August). The Problem of Measuring SES on Educational Assessments. Paper presented at the 100th Annual Meeting of the American Sociological Association, Philadelphia, PA.

McDermott, P. A. (1984). Comparative functions of preschool learning style and IQ in predicting future academic performance. Contemporary Educational Psychology, 9(1), 38-47. doi: 10.1016/0361-476X(84)90006-7

McGinnis, A. M. (2009). Student behaviors as predictors of later academic achievement: School entry through fifth grade (Doctor Dissertation). Available from ProQuest Dissertations and Theses database. (UMI No. 3380966) 
McNeal, R. B. (2012). Checking in or checking out? Investigating the parent involvement reactive hypothesis. The Journal of Educational Research, 105(2), 79-89. doi:10.1080/00220671.2010.519410

Memiş, A. D., \& Kandemir, H. (2019). The relationship between the study habits and attitudes and metacognitive reading comprehension self-awareness, reading comprehension, reading Attitudes. World Journal of Education, 9(4), 133-145. doi: 10.5430/wje.v9n4p133

Ogbodo, R. O. (2010). Effective study habits in educational sector: Counselling Implications. Edo Journal of Counselling, 3(2), 230-242. doi: 10.4314/ejc.v3i2.63610

OECD. (2009). PISA 2006 Technical Report. PISA, OECD Publishing, Paris.

OECD. (2012). PISA 2009 Technical Report. PISA, OECD Publishing, Paris. doi: $10.1787 / 9789264167872$-en

OECD. (2013). PISA 2012 assessment and analytical framework: Mathematics, reading, science, problem solving and financial literacy. PISA, OECD Publishing, Paris. doi: $10.1787 / 9789264190511$-en

Peng, X. Z. (2004). Dui xuexi pinzhi de jiegou yu peiyang celue de yanjiu [Construction of learning quality and its cultivation tactics]. Tangshan Shifan XueyuanXuebao, 26, 75-79.

Renninger, K. A., Hidi, S., \& Krapp, A. (1992). The role of interest in learning and development. The American Journal of Psychology, 107(2), 319-323. doi: 10.2307/1423047

Rogers, C. R. (1965). Some questions and challenges facing a humanistic psychology. Journal of Humanistic Psychology, 5(1), 1-5. doi: 10.1177/002216786500500101

Schweinhart, L. J., Berruetaclement, J. R., Barnett, W. S., Epstein, A. S., \& Weikart, D. P. (1985). Effects of the perry preschool program on youths through age 19: A summary. Topics in Early Childhood Special Education, 5(2), 26-35. doi: 10.1177/027112148500500204

Schweinhart, L. J. (1993). Significant benefits: The high/scope perry preschool study through age 27. Monographs of the high/scope educational research foundation, No. Ten. Monograph Series, High/Scope Educational Research Foundation, 600 North River Street, Ypsilanti, MI 48198-2898.

Schweinhart, L. J., \& Weikart, D. P. (1997). Lasting differences: The high/scope preschool curriculum comparison study through age 23. Monographs of the high/scope educational research foundation, No. Twelve. Monograph Series, High/Scope Foundation, 600 North River Street, Ypsilanti, MI 48198-2898.

Shen, Y., Yang, L. Z., \& Fang, L. L.(2015). 3-6 sui ertong ziwo kongzhi fazhan tedian jiqi jiaoyu jianyi [The Developmental Characteristics and Education Advice of 3-6 Years Old Children's Self Control]. Jiaoyu Kexue [Education Science], 1, 68-74.

Shenzhen Education Bureau. (2014, June 30). Guidance on further improving the comprehensive literacy of primary and secondary school students. Retrieved from http://szeb.sz.gov.cn/xxgk/flzy/wjtz/201406/t20140630_2785792.htm

Sojourner, J., \& Kushner, S. N. (1997, March). Variables that impact the education of african american students: Parental involvement, religious socialization, socioeconomic status, self-Concept, and gender. Paper presented the Annual Meeting of the American Educational Research Association, Chicago, IL, Retrieved from https://files.eric.ed.gov/fulltext/ED410326.pdf

Xiu, R. (2009). Gaozhongsheng xuexi dongji, zixinxin, yu xuexi zeren zhijian de xiangguan yanjiu [The relationship of learning motivation, self-confidence and responsibility of academy in high school students]. Neimonggu Shifan Daxue [Master's thesis, Huhehaote, Inner Mongolia, China. Inner Mongolia Normal University].

Yan, Z. P. (2015). Gaozhongsheng shuxue xuexi xingqu, siwei pinzhi, xueye chengji jiqi guanxi de yanjiu [The relationship between mathematics learning interest, thinking quality, academic achievement in senior high school students]. (Doctoral dissertation, Xihua Normal University, Sichuan, China).

Zhang, G. C. (2000). Guanyu woguo xiaoxuesheng xueye fudan guozhong wenti de dute shenshi [A unique perspective of the problem of excessive academic burden of primary school students in China]. Jiaoyu Kexue, 3, 13-16.

Zheng, B. R. (1996). Lun xuexi jiaoyu [Talking about learning education]. Tianjing shehui kexue yuan chubanshe. 
Zhong, H. Y. (2016). Tan xioxue yuwen "zixin ketang" jiaoxue moshi de goujian [On the construction of the teaching mode of "confidence class" in primary school Chinese]. Gansu Jiaoyu, 8, 95-95.

Zhou, Y. (2016). Gaozhongsheng waibu dongji, ziwoxiaoneng gan, he zizhuxing de guanxi jiqi dui xueye chengji de yingxiang - jiyu zhongbu diqu moshi 46 suo zhongxue de zongxiang shuju [The relationship between high school students' external learning motivation, self-efficacy and autonomy and their influence on academic performance - based on longitudinal data of 46 middle schools in central China]. Jiaoyu Celiang yu Pingjia, 7, 60-64. doi:10.16518/j.cnki.emae.2016.07.012.

\section{ACKNOWLEDGEMENTS}

The data in the study are based on the large-scale assessment conducted by Collaborative Innovation Center of Assessment for Education Quality at Beijing Normal University. The authors are grateful to the colleagues, who helped to collect the data. We extend our thanks to all the students who were willing to take part in this study. We also express gratitude to the reviewers, who gave us valuable suggestions.

\section{AUTHORS' INFORMATION}

Full name: Chuang Wang

Institutional affiliation: Faculty of Education, University of Macau

Institutional address: Room 4002, Faculty of Education, University of Macau, E33, Av. da Universidade, Taipa, Macau, China

Short biographical sketch: Chuang Wang is Distinguished Professor and Dean of the Faculty of Education at the University of Macau. His expertise includes educational research design, statistical data analyses, and program evaluation. He has published 7 books, 19 book chapters, 125 peer-reviewed journal articles, and 12 conference proceedings. Dr. Wang is the recipient of the 2019 International Education Award and the 2018 Harshini V de Silva Graduate Mentor Award at University of North Carolina at Charlotte in the United States. He received the 2008 American Educational Research Association (AERA) Distinguished Paper Award, 2009 Excellence in Research Award from the College of Education, 2010 Distinguished Research Award from the U.S. Academy of Educational Leadership, and the 2012 College of Education Excellence in Teaching Award. He also served as the President of the Chinese American Educational Research and Development Association (2008-2010).

Full name: Qimeng Liu

Institutional affiliation: Collaborative Innovation Center of Assessment for Education Quality, Beijing Normal University

Institutional address: Room 9506, Jingshi Building, 19 Xinjiekouwai Street, Haidian District, Beijing, China

Short biographical sketch: Dr. Qimeng Liu is a lecturer at Beijing Normal University. His research focuses on mathematics education. His publications appeared in top journals in the field of mathematics education. Dr. Liu examined the relationship between problem-raising and self-efficacy on mathematics during his doctoral program. He is also establishing the index system of education innovation in China, which aims to make a contribution to the field of educational innovation. 
Full name: Jian Liu

Institutional affiliation: Collaborative Innovation Center of Assessment for Education Quality, Beijing Normal University

Institutional address: Room 9506, Jingshi Building, 19 Xinjiekouwai Street, Haidian District, Beijing, China

Short biographical sketch: Dr. Jian Liu is a professor of Beijing Normal University (BNU), the deputy director and chief expert of Collaborative Innovation Center of Assessment for Education Quality at BNU. He is also the Dean of China Education Innovation Institute, the director of The Central of Jiusan Society of Special Committee on Education and Culture, the state superintendent of schools in China, and the chief editor of New Century Primary School Mathematics Textbooks. His areas of research include mathematics education, educational innovation, and educational evaluation. Dr. Liu has published in the top-tier journals such as the Journal of Educational Psychology.

Full name: Tianxue Cui

Institutional affiliation: Faculty of Education, University of Macau

Institutional address: Faculty of Education, University of Macau, E33, Av. da Universidade, Taipa, Macau, China

Short biographical sketch: Miss Tianxue Cui is currently a first-year PhD student at the Faculty of Education, University of Macau. Her research focuses on large-scale assessment and family education. She is interested in topics such as educational evaluation, assessment, parental involvement, and educational reform. 